\title{
UNDERWATER DAYLIGHT MEASUREMENTS IN THE BAY OF BISCAY
}

\author{
By B. P. Boden, E. M. Kampa and J. M. Snodgrass \\ University of California, Scripps Institution of Oceanography, La Jolla, California
}

(With Plate I and Text-figs. I-8)

As modern instrumentation improves the precision of the measurements of underwater light, particularly of monochromatic light, both biological and physical oceanographers are becoming increasingly interested in such measurements in deep water.

Two sets of observations of ambient light to depths of $400 \mathrm{~m}$ are presented here. It is suggested that the results were affected by both biological and physical factors.

\section{MATERIALS AND METHOD}

The light measurements were made by means of a telerecording bathyphotometer. There have been previous references in the literature (Kampa \& Boden, 1956; Boden \& Kampa, I957, etc.) to a manuscript description of this instrument by Snodgrass, Cawley \& Devereux. This account was never published and, since the instrument has now been modified, it is here described. This instrument comprises two units-an underwater unit and a deck unit.

The underwater unit (P1. I A, B) is housed in a stainless-steel tube with walls $\frac{1}{2}$ in. thick and consists of a photosensor (RCA 93I-A multiplier phototube) with a shutter, a depth sensor, a temperature sensor, control circuits and power supply, and the telemetering circuit by which light, depth, and temperature information are transmitted. It is supported by an insulated, single-conductor cable along which the data are telemetered. There are several advantages to the use of this type of cable. It is extremely strong (breaking strain $2800 \mathrm{lb}$.) and can be wrapped on a relatively small winch ( $800 \mathrm{lb}$. total weight). Due to the buoyancy of the polythene insulation the weight of this cable in water is only $\mathrm{I} 6 \mathrm{lb}$./1000 ft. In multi-channel cable there is always a danger of short-circuits between the conductors due to mechanical stresses on the winch or block. This is eliminated here. The system uses a sea return.

Signals from the cable are transmitted via slip-rings on the winch to the deck unit.

The deck unit (P1. I C) includes the circuitry that enables the operator to select the function (light, depth or temperature) to be recorded, a number of 
bias circuits for zeroing the instrument, and a recorder (P1. I D) to which the information is relayed.

The connexions are summarized in Text-fig. I.

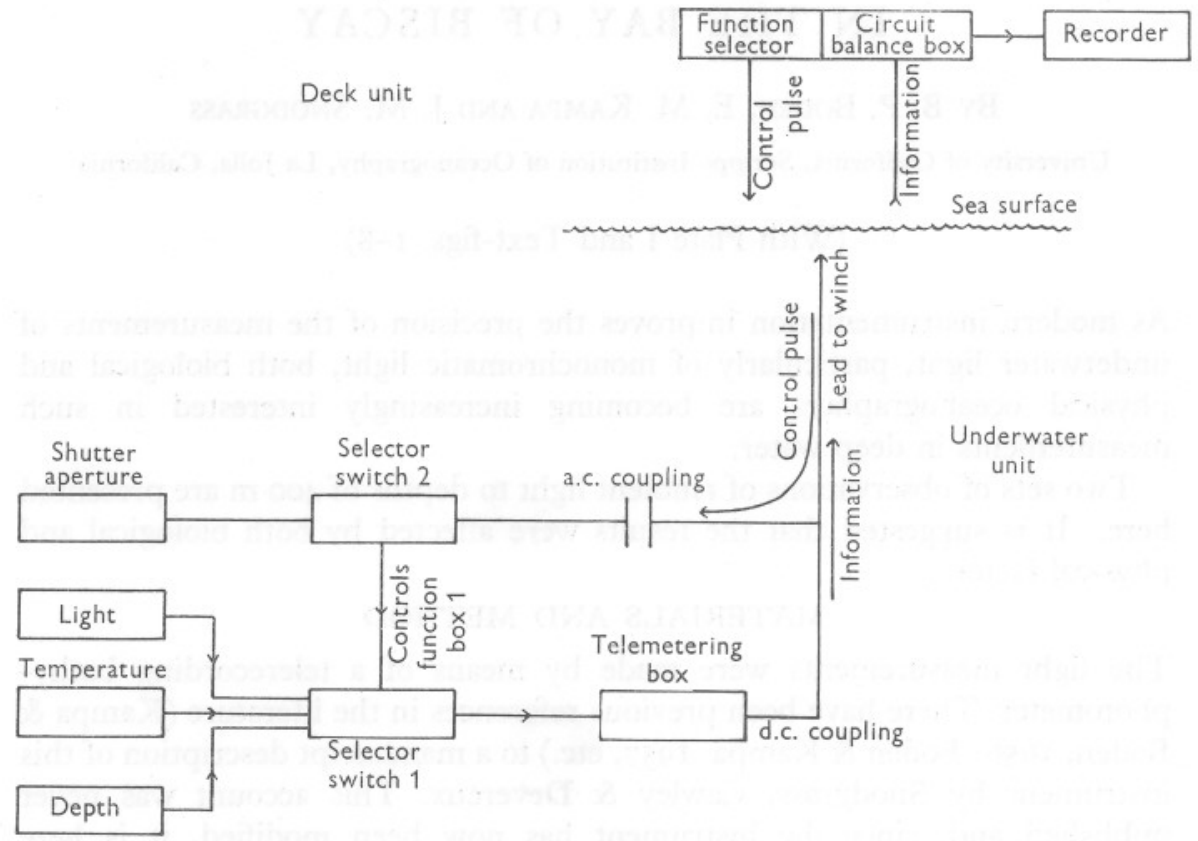

\section{Circuits}

Text-fig. I

Circuit diagrams for the entire instrument are shown in Text-figs. 2-4. The photometric circuitry (modified from Sweet, 1946) gives a logarithmic response over seven decades of light intensity.

The use of a pentode tube as a telemetering coupler (Valley \& Wallman, I948) obviates the interference of various potentials in the earth circuit, such as potentials between the steel hull of the ship and bronze propellor shafts and the water.

Depth

This element is a Bourdon tube coupled to a slide-wire potentiometer. It has been described elsewhere (Boden, Kampa, Snodgrass \& Devereux, 1955).

\section{Temperature}

Water temperature is measured by a matched pair of I4-A thermistors, which operate in opposite arms of a full-resistance bridge. The bridge unbalance potential is applied directly to the grid of the IV 5 telemetering tube through a stepping switch.

\section{EXPLANATION OF PLATE 1}

A, underwater unit of photometer without case. B, underwater unit in case with collimating tube and automatic filter changer in position. The unit is connected by a test lead to $\mathrm{C}$, the deck control unit, which is connected to D, a Leeds and Northrup Speedomax recorder. 


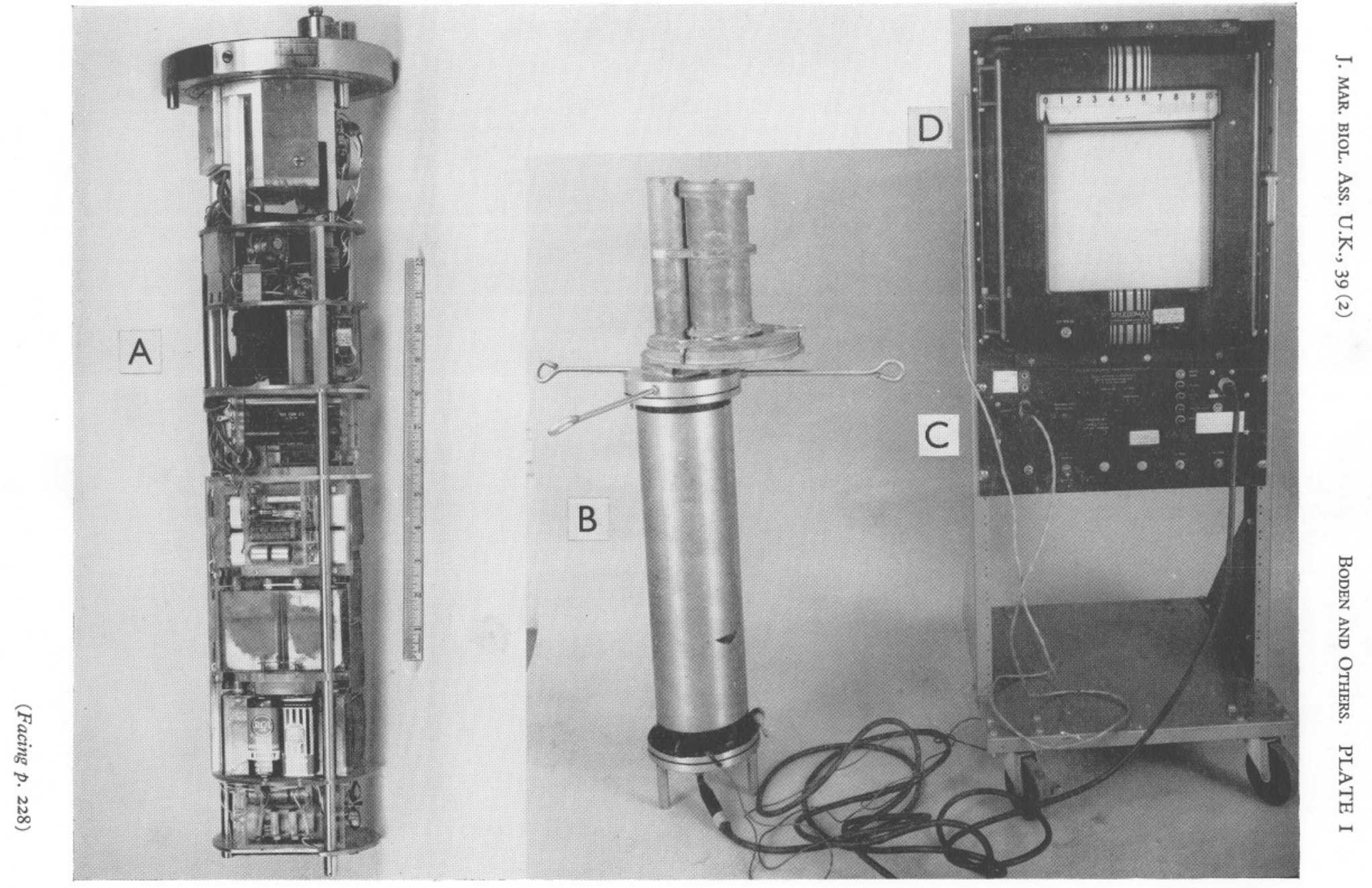




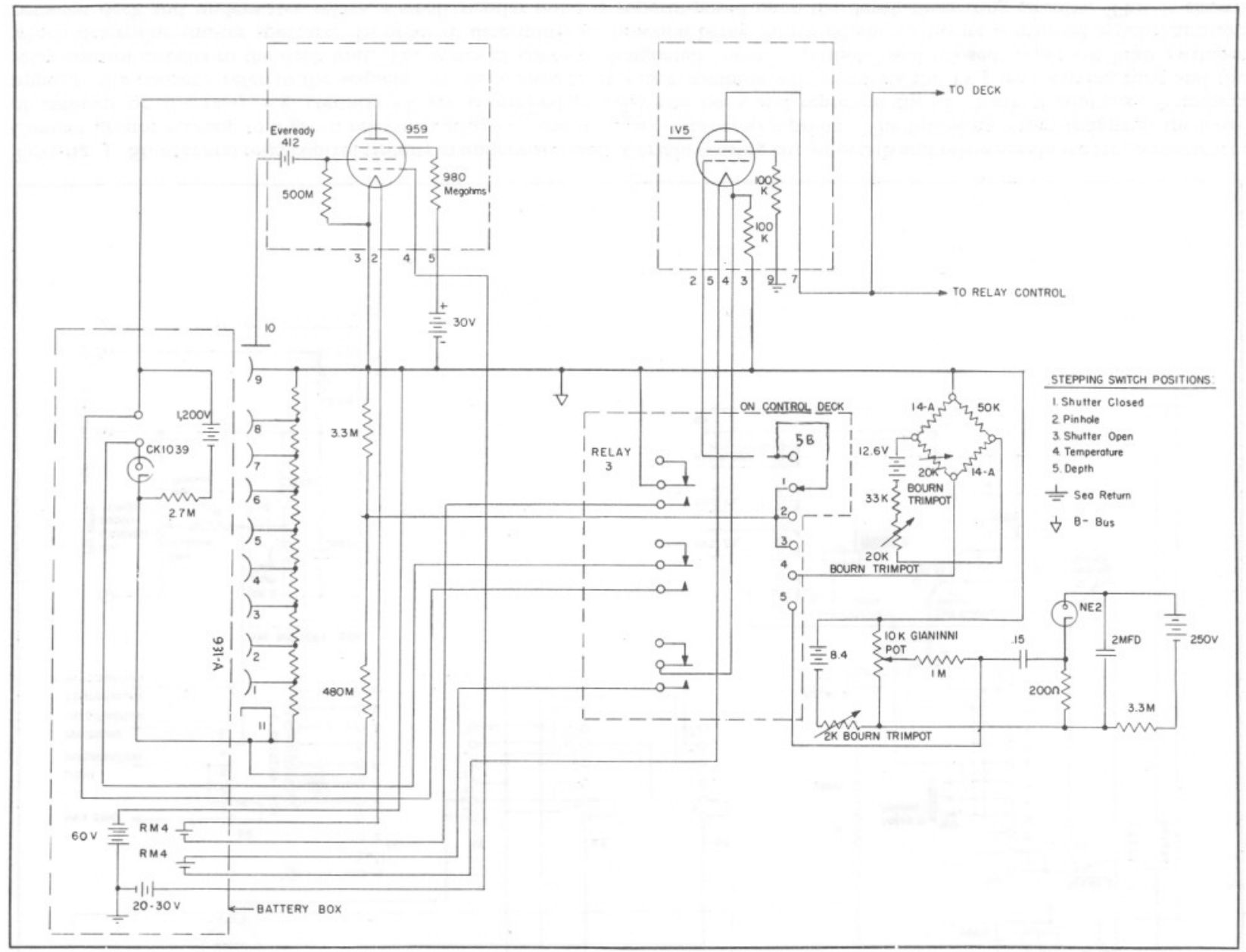

Text-fig. 2. Sensing circuits-depth, temperature and light. The assembly consists of the multiplier phototube (93I-A) with its associated glow-type regulator (CK IO39) which is coupled to the type 959 control tube. The batteries are turned on and off from the deck unit by means of the multiple contacts on relay 3 . The IV 5 tube is the telemetering coupler. The stepping switch relay 5 selects the desired function. The contacts designated under $5 \mathrm{~B}$ constitute one deck of this stepping switch. Connected immediately to this deck are the outputs from the photomultiplier control tube, the thermistor temperature bridge, and the depth potentiometer. For interconnexion of controls see Text-fig. 3 . 


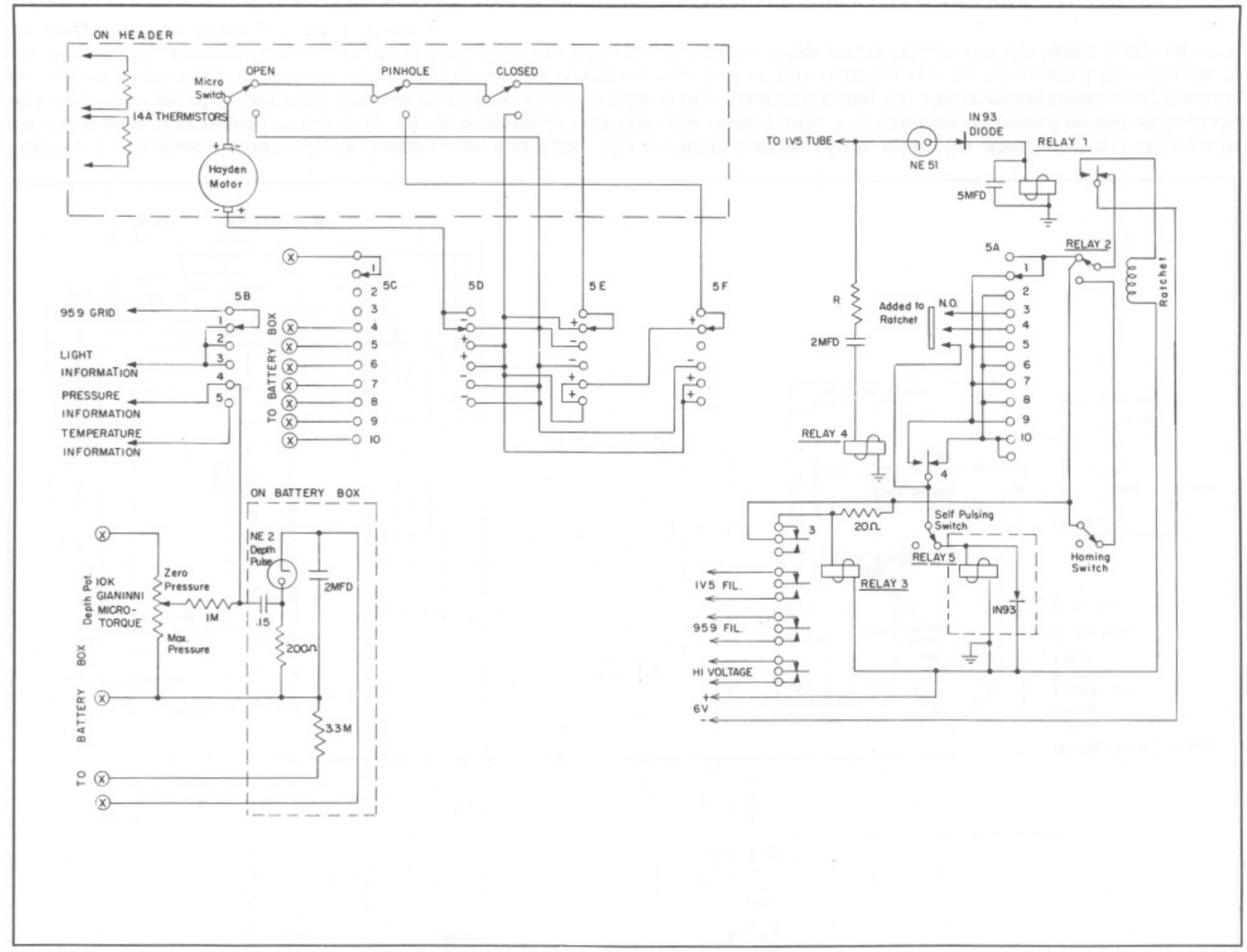

Text-fig. 3. Shutter and relay control circuits in underwater unit. Certain sensing circuit details and relays are shown for convenience. Contact groups relating to a given relay-actuating coil use the relay number as a prefix. The following letter designates the bank of contacts on the relay, e.g. contacts $5 \mathrm{E}$ are controlled by relay coil no. 5 and represent the ' $\mathrm{E}$ ' bank of contacts. Numbers opposite the contacts refer to the sequence of the contacts. A single common wire connects the IV 5 telemetering tube and the relay control circuits to the deck unit. The series of contacts designated 'open', 'pinhole' and 'closed' represent limit switches which determine shutter aperture. In order to determine the function being measured and to insure continued synchronization between deck and underwater relays, a small regular pulse is superimposed upon the depth-measuring circuits. This is shown as a simple relaxation oscillator. 


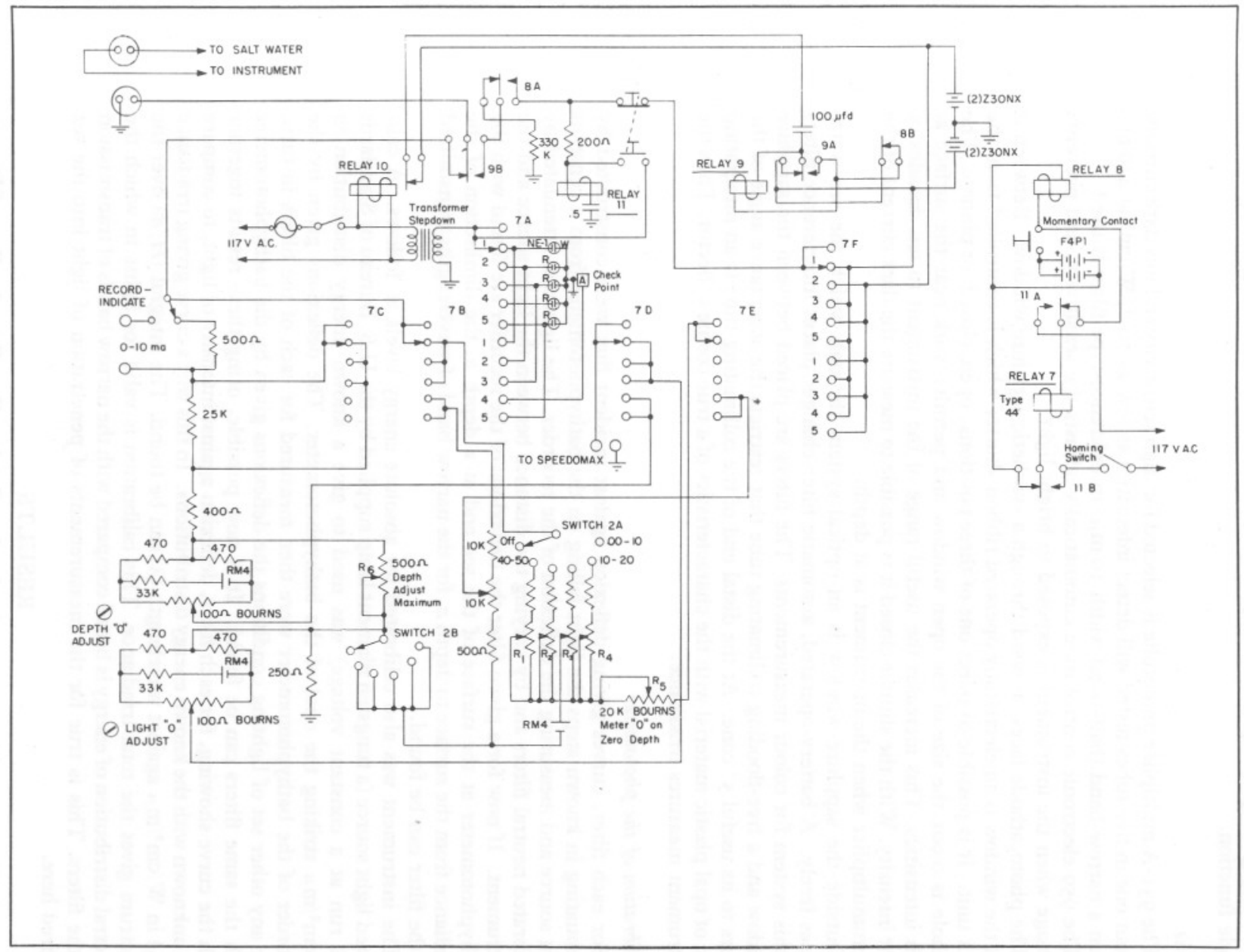

Text-fig. 4. Deck control unit. The same designations are followed as in Text-fig. 3. In order to indicate the function being measured and to insure synchronization between deck and underwater units, two identical stepping switches are pulsed in series. These are relays 5 (in the underwater unit) and 7 (in the deck unit). To insure the operator's safety an isolating step-down transformer is used between the circuits and the II $7 \mathrm{~V}$ a.c. power supply. Numerous range-adjusting and balancing networks are incorporated for convenience of read-out. A ground symbol indicates a good sea-water contact. The string of neon lamps connected to contacts $7 \mathrm{~A}$ indicate the function being measured. 
The stepping switch controls shutter position and also permits programmed telemetering of light, depth and temperature, or continuous recording of any selected single function.

\section{Light}

The 93I-A multiplier phototube is selected for high sensitivity and low dark current. About one in five tubes tested will detect intensities as low as $10^{-5} \mu \mathrm{W} / \mathrm{cm}^{2}$ at $420 \mathrm{~m} \mu$ when a narrow band (half-band width $\mathrm{I} 0 \mathrm{~m} \mu$ ) interference-type filter is used.

The 959 electronic control tube automatically adjusts the sensitivity, and prevents damage when the instrument is exposed to bright light.

The photocathode faces outward through a synthetic sapphire window. Between it and the window is an electrically operated ribbon shutter which is controlled from the deck unit. It is possible to select one of three positions: open, closed, or pinhole. The pinhole is 0.001 the size of the open window and permits work near the surface at high intensities. This increases the useful range of the instrument to ten decades of light intensity. With the shutter closed it is possible to measure the dark current of the photomultiplier when the instrument is at depth.

Outside the sapphire window is an optical system through which the sea water passes freely. A battery-operated, automatic filter-changer places interference filters in this system for colour measurements. The filters are placed between the sapphire window and a free-flooding collimating tube that restricts the acceptance angle of the filters to its useful $5^{\circ}$ cone. At the distal end of the collimating tube is an integrating disc of opal plastic material with the characteristics of a true cosine collector. Thus the instrument measures irradiance.

\section{Calibration of the photometer}

For each filter, curves giving deflexion against incident flux were constructed by attenuating in known steps the light falling on the bathyphotometer from a constant light source and measuring the deflexion of the recorder. The light was attenuated by calibrated neutral filters and by varying the distance between the light source and the instrument. If now for a given filter the deflexions of the recorder are found with the bathyphotometer at the surface of the sea and at a depth $z$, the diminution of the irradiance from the surface to depth $z$, for the narrow band of wavelengths transmitted by the filter can be found.

The instrument was also calibrated for absolute energy levels as follows. A calibrated light source (a tungsten filament lamp supplied by the U.S. Bureau of Standards and run at a constant voltage) was used to give a known energy distribution in $\mathrm{W} / \mathrm{cm}^{2} / \mathrm{m} \mu$ striking the opal of the bathyphotometer. The deflexions given by the recorder of the bathyphotometer were then measured for each of the filters in turn. For any other set of lighting conditions the deflexions given by the bathyphotometer with the same filters can be found. It is now possible, using these results together with the curve showing, for each filter, deflexion against intensity of light, to compare the unknown with the known energy distributions. In this way a curve giving irradiance $\left(H_{\lambda}\right)$ in $\mathrm{W} / \mathrm{cm}^{2} / \mathrm{m} \mu$ against wavelength $(\lambda)$ can be found. The integral $\int H_{\lambda} d \lambda$ over the spectrum gives the total irradiance. This calibration is valid for lights in which the spectral distribution of energy is broad compared with the narrow bands of transmission of the filters. This is true for the measurements of penetration of light into the sea desired here.

\section{RESULTS}

The results reported here were obtained at Station Cavall in the Bay of Biscay (lat. $46^{\circ} 29^{\prime}$ N., long. $7^{\circ} 59^{\prime}$ W.) on 25 September 1958, from the Plymouth 
laboratory R.V. 'Sarsia'. Station Cavall is one of several hydrographic stations established by Dr L. H. N. Cooper during his investigation of this area, and it was occupied for several days at this time.

The bathyphotometer was lowered twice during the day. The morning cast was made between IO.30 and II. $30 \mathrm{~h}$ and the afternoon cast between $\mathrm{I} 3.25$ and I4. $\mathrm{IO} \mathrm{h}$. The interference filters used in the morning cast had pass bands with peaks at $434,460,49 \mathrm{I}, 5 \mathrm{I} 4$ and $540 \mathrm{~m} \mu$. Those used in the afternoon transmitted maximally at $42 \mathrm{I}, 470,482,498$ and $528 \mathrm{~m} \mu$.

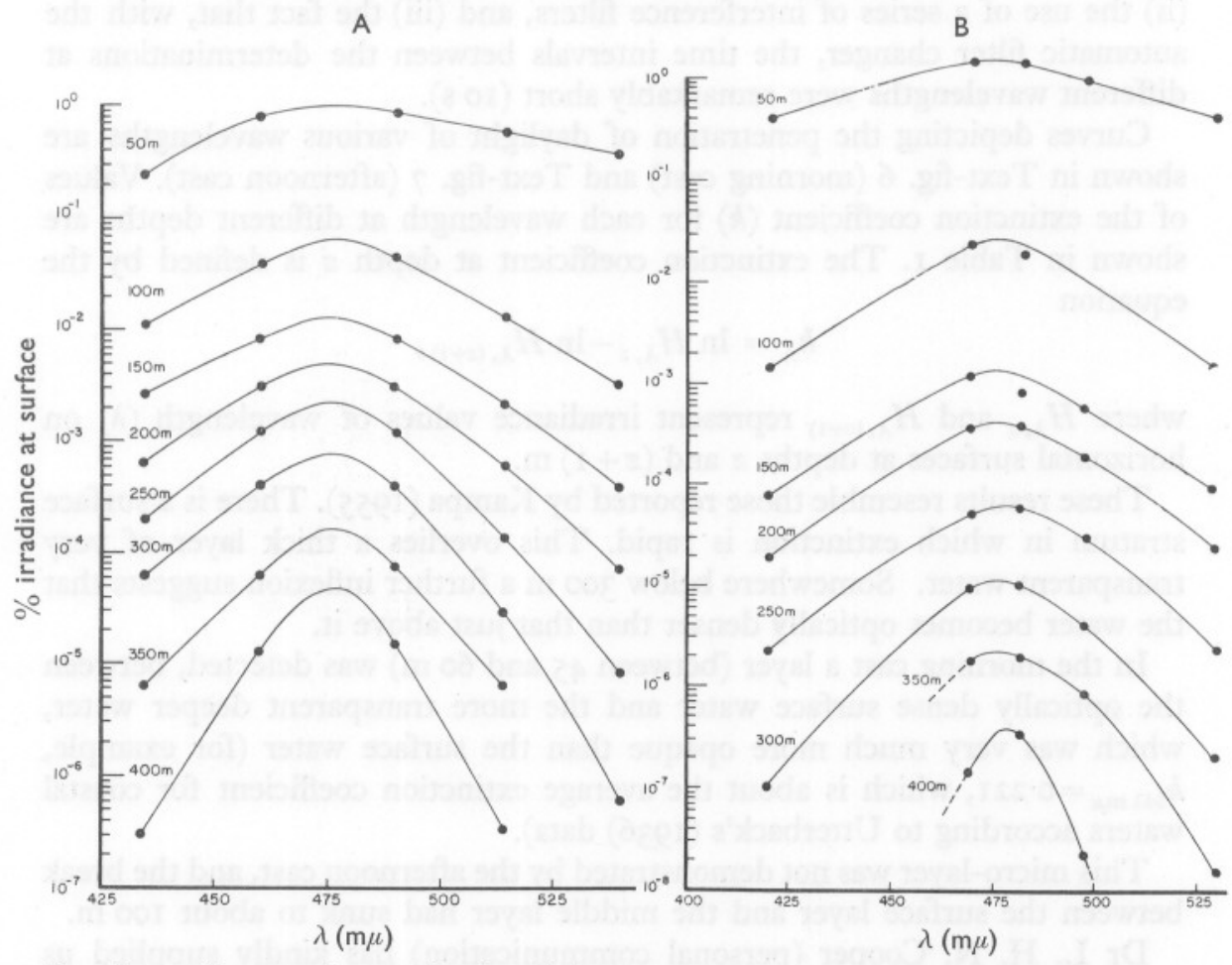

Text-fig. 5. Spectra of transmitted sunlight at $50 \mathrm{~m}$ intervals of depth in the Bay of Biscay (lat. $46^{\circ} 29^{\prime}$ N., long. $7^{\circ} 59^{\prime}$ W.) on 25 September I958. A, I0.30-II.30 h G.M.T.; B, I3.25I4.IO h G.M.T.

At this latitude, at this time of the year, differences in degree of underwater irradiance due to differences in the sun's altitude at periods as closely spaced as these during the middle of the day are less than $5 \%$. However, sky conditions changed between the two casts. In the afternoon a light, high haze caused some forward scattering. The afternoon irradiance values are higher than those obtained in the morning, but this is not a matter of importance, since the values have been equated to $I$ at the surface, and only relative values are considered. 
The spectral composition of the light at $50 \mathrm{~m}$ intervals to a depth of $400 \mathrm{~m}$ is shown in Text-figs. 5A, B. The distribution obtained in the morning is very similar to that obtained in the afternoon, although different sets of filters were used. The light becomes steadily bluer with depth until at $400 \mathrm{~m}$ the spectrum peaks sharply between 475 and $480 \mathrm{~m} \mu$. This is an excellent illustration of the ocean acting as a monochromator as described by Tyler (1959). These results agree closely with those obtained by Jerlov (I95I) and the main interest attached to them is: (i) the relatively great depth attained, (ii) the use of a series of interference filters, and (iii) the fact that, with the automatic filter changer, the time intervals between the determinations at different wavelengths were remarkably short (IO s).

Curves depicting the penetration of daylight of various wavelengths are shown in Text-fig. 6 (morning cast) and Text-fig. 7 (afternoon cast). Values of the extinction coefficient $(k)$ for each wavelength at different depths are shown in Table I. The extinction coefficient at depth $z$ is defined by the equation

$$
k_{\lambda}=\ln H_{\lambda, z}-\ln H_{\lambda,(z+1)},
$$

where $H_{\lambda, z}$ and $H_{\lambda,(z+1)}$ represent irradiance values of wavelength $(\lambda)$ on horizontal surfaces at depths $z$ and $(z+\mathrm{I}) \mathrm{m}$.

These results resemble those reported by Kampa (1955). There is a surface stratum in which extinction is rapid. This overlies a thick layer of very transparent water. Somewhere below $300 \mathrm{~m}$ a further inflexion suggests that the water becomes optically denser than that just above it.

In the morning cast a layer (between 45 and $60 \mathrm{~m}$ ) was detected, between the optically dense surface water and the more transparent deeper water, which was very much more opaque than the surface water (for example, $k_{541 \mathrm{~m} \mu}=0.221$, which is about the average extinction coefficient for coastal waters according to Utterback's (1936) data).

This micro-layer was not demonstrated by the afternoon cast, and the break between the surface layer and the middle layer had sunk to about $100 \mathrm{~m}$.

Dr L. H. N. Cooper (personal communication) has kindly supplied us with the data showing the vertical thermal structure (Text-fig. 8) at the time of the casts. Our thermistor circuit failed during the operation, and we did not record temperature. It can be seen that there was a very strong thermocline somewhere between 40 and $97 \mathrm{~m}$. Correlations between attenuation coefficients and thermoclines in the north Pacific have been reported by M. Koslyaninov (Academy of Sciences, U.S.S.R.-personal communication to $\mathrm{Mr}$ J. E. Tyler, Scripps Institution).

Between the morning and afternoon casts the wind had increased from force 3 to force 4 and the sea from state 3 to state 5 . The ship drifted less than 6 miles between casts and the possibility that this resulted in the sampling of different water masses at an oceanic station is slight. 


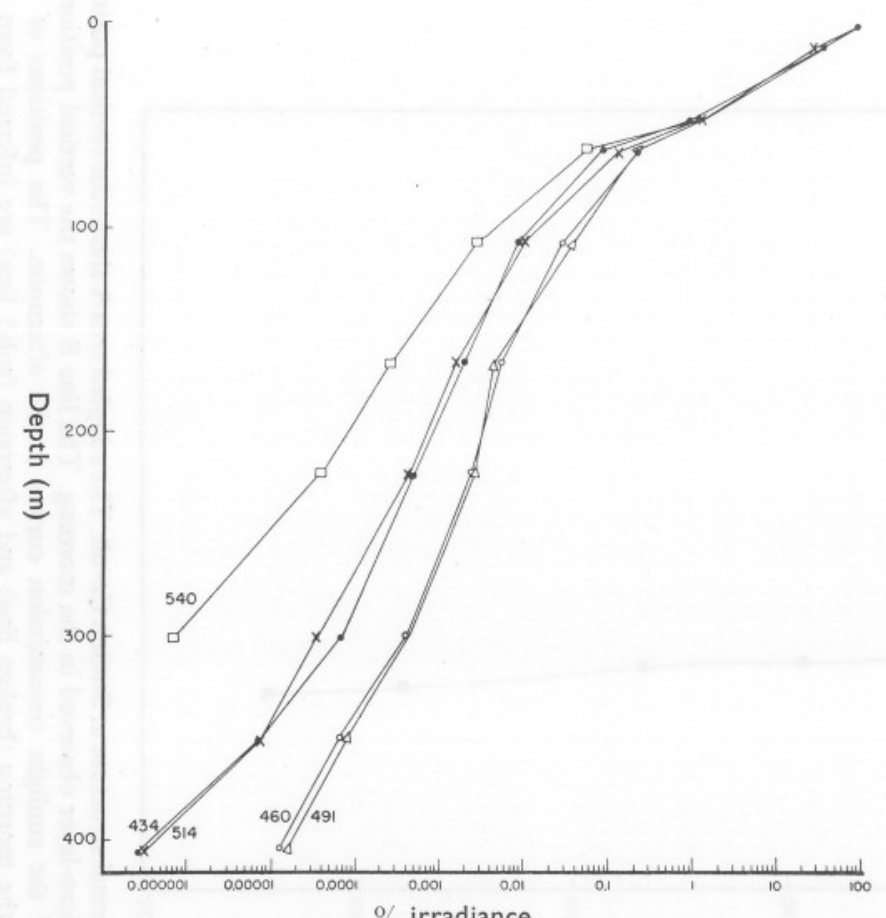

$\%$ irradiance

Text-fig. 6. Relation between depth and irradiance at various wavelengths expressed as percentage of irradiance values at the surface.

The numbers at the ends of the curves indicate the wavelengths $\vec{n}($ in $\mathrm{m} \mu$ ) of maximum transmission of the interference filters used.

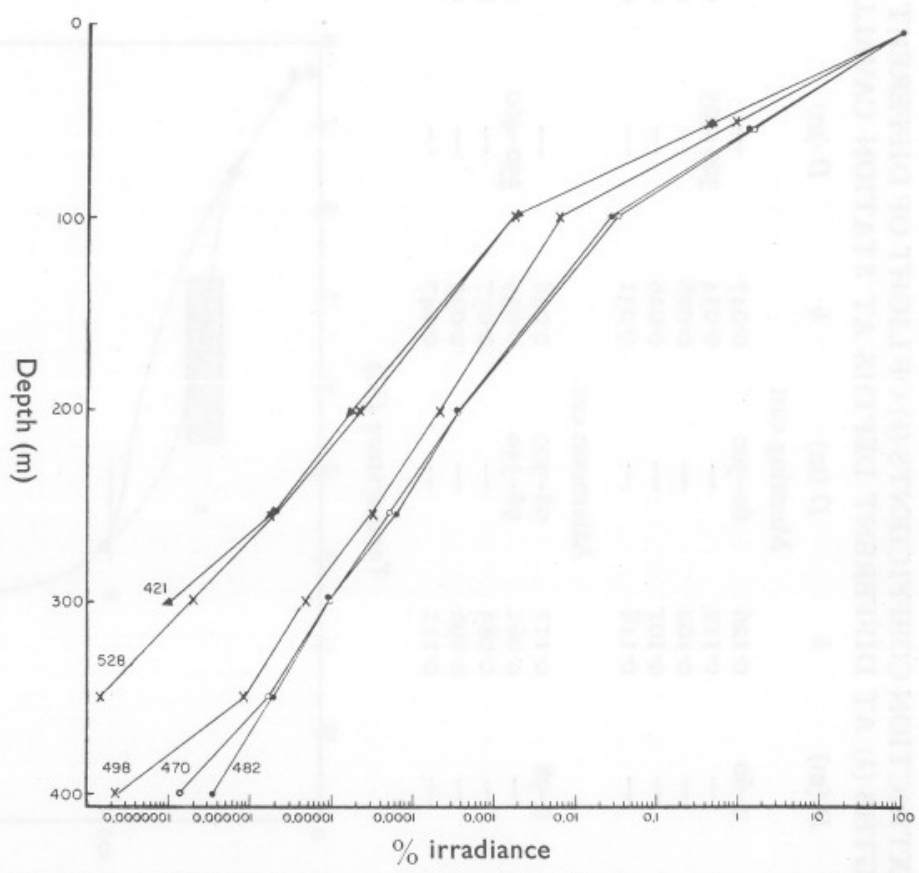

Text-fig. 7. Relation between depthand irradiance at various wavelengths expressed as percentage of irradiance values at the surface. The numbers at the ends of the curves indicate the wavelengths (in $\mathrm{m} \mu$ ) of maximum transmission of the interference filters used 
TABLE 1. EXTINCTION COEFFICIENTS $(k)$ OF LIGHT OF DIFFERENT WAVELENGTHS $(\lambda)$ AT DIFFERENT DEPTHS AT STATION CAVALL

$\begin{array}{ccccccc}\lambda(\mathrm{m} \mu) & D(\mathrm{~m}) & k & \begin{array}{c}D(\mathrm{~m}) \\ \text { Morning cast }\end{array} & k & D(\mathrm{~m}) & k \\ 540 & 0-60 & 0.126 & 60-300 & 0.047 & - & - \\ 514 & - & 0.112 & - & 0.034 & 300-405 & 0.045 \\ 491 & = & 0.102 & - & 0.026 & - & 0.032 \\ 460 & = & 0.101 & - & 0.026 & - & 0.033 \\ 434 & - & 0.118 & - & 0.031 & - & 0.052 \\ & & & \text { Afternoon cast } & & & \\ 421 & 0-98 & 0.111 & 98-300 & 0.048 & - & - \\ 470 & - & 0.081 & 98-350 & 0.039 & 350-400 & 0.050 \\ 482 & - & 0.083 & - & 0.037 & - & 0.035 \\ 498 & - & 0.096 & - & 0.035 & - & 0.072 \\ 528 & - & 0.111 & - & 0.047 & - & -\end{array}$

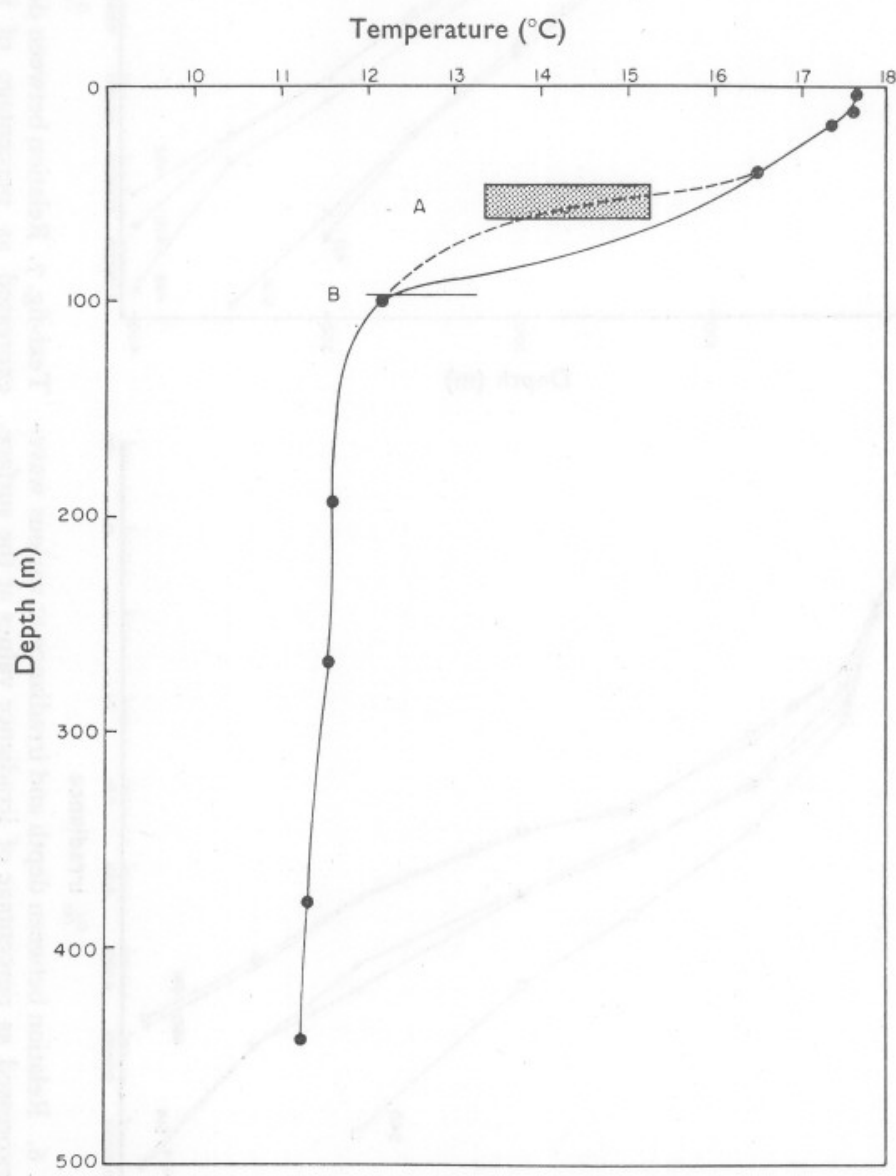

Text-fig. 8. Thermal structure at Station Cavall. The stippled area A shows the vertical position of the turbid micro-layer observed in the morning. The line B shows the vertical position of the inflexion of the sunlight transmission curves in the afternoon. The positions of the thermocline in the morning (broken line) and afternoon (solid line) are inferred from the optical data. 
We interpret this apparent destruction of the optically dense micro-layer and the sinking of the break between the surface and middle layers as being due to turbulence associated with this change in the weather. The high extinction coefficients in the surface layer could well have been caused by particulate matter due to the higher productivity of the layer. The vertical extent of this layer is consistent with the depth of the 'photic' zone (Hedgpeth, I958) at this latitude. The sharp difference in the optical properties of the two layers was probably due to an accumulation of particulate matter at an interface associated with an apparently long-established thermocline.

TABLE 2. OXYGEN VALUES AT DIFFERENT DEPTHS AT STATION CAVALL

\begin{tabular}{|c|c|c|c|}
\hline \multirow[b]{2}{*}{$D(\mathrm{~m})$} & \multicolumn{3}{|c|}{ Oxygen } \\
\hline & $\mathrm{ml} . / 1$. & $\begin{array}{c}\% \\
\text { sat. }\end{array}$ & $\begin{array}{l}\text { Defect } \\
\text { (ml./l.) }\end{array}$ \\
\hline $\begin{array}{r}97 \\
100 \\
193 \\
268 \\
381 \\
442 \\
537\end{array}$ & $\begin{array}{l}5.52 \\
5.45 \\
5.57 \\
5.59 \\
5.38 \\
5.32 \\
5.02\end{array}$ & $\begin{array}{l}93 \cdot 6 \\
94 \cdot 8 \\
94 \cdot 6 \\
95 \cdot 0 \\
90 \cdot 7 \\
89 \cdot 6 \\
83 \cdot 9\end{array}$ & $\begin{array}{l}0.37 \\
0.30 \\
0.32 \\
0.29 \\
0.55 \\
0.62 \\
0.96\end{array}$ \\
\hline
\end{tabular}

Such turbulence would cause a slight sinking of the thermocline and this change in thermal structure is summarized in Text-fig. 8. The broken line shows the probable position of the thermocline in the morning, and the solid line the same in the afternoon. The shaded area (A) represents the turbid micro-layer present in the morning, and a line (B) shows the break between the optical properties of the upper and lower layers in the afternoon. This increase in the vertical extent of the surface layer would result in a greater dilution of the particles in it, and this is revealed by somewhat lower extinction values in this layer in the afternoon. The differences in extinction coefficients between the middle and lower layers, somewhere below $300 \mathrm{~m}$, are less pronounced.

In California, Kampa (I955) found that the lower inflexion in the extinction curve was associated with the top of a sonic-scattering layer and inferred that this increased extinction was also of biological origin. We have no evidence of the existence of a sonic-scattering layer at Station Cavall at this time, but this does not preclude the possibility that one was present. The echo-sounder on the 'Sarsia' operates at a much shorter ping-length than most American instruments, and may well have not recorded a layer of the type found in California.

Cooper, who supplied the oxygen data in Table 2, writes 'between 268 and $391 \mathrm{~m}$ there was some evidence, particularly from oxygen, of a change in properties. It was not very marked, however'. It is apparent that the photometer entered a water mass with different optical properties at about 
this depth. Whether such changes in oxygen content and transparency are linked with some biological phenomenon is a moot point. There were no marked changes in temperature, salinity, or other properties at this depth.

This work was done under contract between the U.S. Office of Naval Research and the University of California. A grant-in-aid was made by the U.S. National Science Foundation. Part of the work was supported by the U.S. Bureau of Ships.

We wish to thank the Director, Dr F. S. Russell, F.R.S., for the unfailing hospitality of the Plymouth Laboratory, the scientific staff of the laboratory and the captain, officers and crew of the R.V. 'Sarsia' for their help under rather trying circumstances. Dr L. H. N. Cooper, for whom the cruise was scheduled, was extremely generous in granting us time and in making available the pertinent hydrographic data.

\section{SUMMARY}

A telerecording bathyphotometer embodying a multiplier phototube is described and the circuitry is illustrated. Measurements were made of the penetration and spectral characteristics of daylight to a depth of $400 \mathrm{~m}$ in the Bay of Biscay. It is suggested that the rapid attenuation of light in the upper IOO $\mathrm{m}$ was due in part to biological matter associated with a sharp thermocline. A change in the weather is presumed to have caused a change in the depth of the thermocline and this is reflected in a change in attenuation coefficients.

\section{REFERENCES}

Boden, B. P., Kampa, E. M., Snodgrass, J. M. \& Devereux, R. F., 1955. A depth telerecording unit for marine biology. F. mar. Res., Vol. I4, pp. 205-9.

BodEN, B. P. \& KAMPA, E. M., 1957. Records of bioluminescence in the ocean. Pacif. Sci. Vol. II, pp. 229-35.

HEDGPETH, J. L. (Ed.), I958. Treatise on marine ecology and paleoecology. I. Ecology. Mem. geol. Soc. Amer., No. 67, Vol. I, I296 pp.

JerLov, N. G., I951. Optical studies of ocean waters. Rep. Swedish deep-sea Exped., Vol. 3, Phys. and Chem., Fasc. I, pp. I-59.

KAMPA, E. M., I955. A discrepancy between calculation and measurement of submarine illumination. Proc. nat. Acad. Sci., Wash., Vol. 4I, pp. 938-939.

KAMPA, E. M. \& BoDEN, B. P., I956. Light generation in a sonic-scattering layer. Deep-Sea Res., Vol. 4, pp. 73-92.

SwEET, M. H., 1946. Logarithmic photometer. Electronics, Vol. 19, pp. 106-109.

TYLER, J. E., I959. Natural water as a monochromator. Limnol. Oceanogr., Vol. 4, No. I, pp. 102-105.

UtTERBACK, C. L., 1936. Spectral bands of submarine solar radiation in the North Pacific and adjacent inshore waters. Rapp. Cons. Explor. Mer, Vol. Ior, Pt. 2, No. 4 , I5 pp.

Valley, G. E. \& Wallman, H., 1948. Vacuum Tube Amplifiers. New York: McGraw Hill. 